\title{
Infecções hospitalares associadas à bacilos gram-negativos não fermentadores em unidade de terapia intensiva: revisão narrativa
}

\author{
Hospital infections associated with non-fermenting gram-negative bacilli in an intensive \\ care unit: narrative review
}

\section{Infecciones hospitalarias asociadas con bacilos gramnegativos no fermentadores en una unidad de cuidados intensivos: revisión narrativa}

Thaylon Menezes Ferreira da Silva ${ }^{1 *}$, Antônio Marcos Adriano Cipriano Filho ${ }^{1}$, Zildenilson da Silva Sousa ${ }^{1}$, José Auberlanio Lima Rodrigues ${ }^{1}$, Natália Viviane Freitas da Silva ${ }^{1}$, Marcelo Matos de Freitas Filho ${ }^{1}$, João Ricardo Gomes Pereira ${ }^{1}$, Sandra Maria dos Santos Pereira Araújo ${ }^{1}$, Shara Teixeira Belarmino Rodrigues', Bruno Nascimento da Silva².

\begin{abstract}
RESUMO
Objetivo: Identificar e revisar as causas de infecções hospitalares associadas a bacilos gram-negativos não fermentadores (BGN-NF) em unidade de terapia intensiva (UTI) e seus métodos de controle e prevenção. Revisão bibliográfica: A taxa de infecção por estes microrganismos é baixa quando comparadas com outros grupos bacterianos, no entanto, se tornam graves pelo fato da alta resistência aos fármacos antimicrobianos. Além disso, fatores como o ambiente físico e tempo de internamento são aspectos ideais para a colonização por estes tipos de bactérias. A diversidade e disseminação podem ser ocasionadas pelo grande fluxo de pacientes submetidos a cirurgias, doença de base, uso dos cateteres urinários e venosos, ventilação mecânica, perfil imunológico, idade e o uso de medicamentos imunossupressores, como também o tratamento empírico com antibióticos e seu uso de forma inadequada podem tornar os pacientes suscetíveis a infecções. Considerações finais: Medidas constantes de esterilização do ambiente e de materiais utilizados para a reabilitação em UTI são fundamentais para a redução do agravamento das taxas de mortalidade em decorrência desta problemática, possibilitando a limitação de aparecimento de microrganismos resistentes aos atuais fármacos existentes, reduzindo assim problemas relacionados a assistência à saúde.
\end{abstract}

Palavras-chave: Bacilos gram-negativos, Infecção nosocomial, Resistência bacteriana.

\begin{abstract}
Objective: Identify and review the causes of hospital diseases associated with non-fermenting gram-negative bacilli (BGN-NF) in an intensive care unit (ICU) and their methods of control and prevention. Bibliographic review: The rate of infection by these microorganisms is low when compared to other bacterial groups, however, it becomes serious due to the high resistance to antimicrobial drugs. In addition, factors such as the physical environment and length of stay are ideal aspects for colonization by these types of bacteria. Diversity and dissemination can be caused by the large flow of patients who have undergone surgery, underlying disease, use of urinary and venous catheters, mechanical capacity, immunological profile, age and the use of immunosuppressive drugs, as well as empirical treatment with antibiotics and their improper use can make patients susceptible to disease. Final considerations: Constant measures of sterilization of the environment and materials used for rehabilitation in the ICU are essential to reduce the worsening of mortality rates as a result of this problem, making it possible to limit the appearance of microorganisms resistant to current existing drugs, problems thus related health care.
\end{abstract}

Keywords: Gram-negative bacilli, Nosocomial infection, Bacterial resistance.

${ }^{1}$ Centro Universitário Maurício de Nassau (UNINASSAU), Fortaleza - CE. *E-mail: thaylon-m@hotmail.com

2 Universidade Federal do Ceará (UFC), Fortaleza - CE. 


\section{RESUMEN}

Objetivo: Identificar y revisar las causas de las infecciones nosocomiales asociadas a bacilos gramnegativos no fermentadores (BGN-NF) en una unidad de cuidados intensivos (UCI) y sus métodos de control y prevención. Revisión bibliográfica: La tasa de infección por estos microorganismos es baja en comparación con otros grupos bacterianos, sin embargo, se agravan por la alta resistencia a los antimicrobianos. Además, factores como el entorno físico y la duración de la estancia son aspectos ideales para la colonización por este tipo de bacterias. La diversidad y diseminación puede estar provocada por el gran flujo de pacientes sometidos a cirugía, enfermedad de base, uso de catéteres urinarios y venosos, ventilación mecánica, perfil inmunológico, edad y uso de fármacos inmunosupresores, así como el tratamiento empírico con antibióticos y su uso inadecuado puede hacer que los pacientes sean susceptibles a infecciones. Consideraciones finales: Las constantes medidas de esterilización del ambiente y los materiales utilizados para la rehabilitación en la $\mathrm{UCI}$ son fundamentales para reducir el agravamiento de las tasas de mortalidad como consecuencia de este problema, permitiendo limitar la aparición de microorganismos resistentes a los fármacos existentes actualmente. reduciendo así los problemas relacionados con la asistencia sanitaria.

Palabras clave: Bacilos gramnegativos, Infección nosocomial, Resistencia bacteriana.

\section{INTRODUÇÃO}

A infecção hospitalar em sua definição está relacionada à infecção no paciente após a sua admissão ao hospital, podendo ser manifesta no período de internação de 72 horas, ou após alta, mas que estão associadas a procedimentos diagnósticos e/ou terapêuticos, realizados durante este período (ARAÚJO PL, et al., 2017). No entanto, já que as infecções não estão limitadas ao ambiente hospitalar foi adotada a terminologia Infecção Adquirida em Serviços de Saúde ou até mesmo Infecções Relacionadas à Assistência à Saúde (IRAS) (MENEGUETI MG, et al., 2015).

Assim, o tempo de permanência dos pacientes em Unidades de Terapia Intensiva (UTI) podem influenciar intrinsicamente na saúde, onde existe uma forte relação do tempo de permanência com a colonização de microrganismos multirresistentes para que ocorram as IRAS, assim, tempo de internação leva o paciente a ser exposto a outros fatores de risco devido sua gravidade clínica, infecção cruzada e procedimentos invasivos (ARAÚJO PL, et al., 2017; POZZATO RS e PARISI MM, 2018).

Os principais patógenos encontrados nas infecções hospitalares são as bactérias gram-positivas, como 0 Staphylococcus coagulase negativa (ECN), Staphylococcus aureus resistente à meticilina (SARM) e Streptococcus pneumoniae, além dos Gram-negativos como a Pseudomonas aeruginosa, Escherichia coli, Enterobacter, Acinetobacter, Klebsiella, Proteus e Stenotrophomonas (POZZATO RS e PARISI MM, 2018; MOTA FS, et al., 2018).

No entanto, um grupo de bactérias de importância hospitalar chamado de bacilos gram-negativos não fermentadores (BGN-NF) tem se destacado (OLIVEIRA MEF, et al., 2017). Habitantes de solo e água, esse grupo pode causar infecções principalmente em imunocomprometidos, além de apresentarem alta resistência a uma ampla variedade de drogas, com destaque para a pseudomonas aeruginosa, Acinetobacter e Stenotrophomonas maltophilia (ADEGOKE AA, et al.,2017).

Infecções geradas no meio hospitalar ou até mesmo nos serviços de saúde têm sido uma grande causa de morbimortalidades em diversos hospitais no mundo (ALVIM ALS, et al., 2019). Tratando-se de BGN-NF, seu papel patogênico e virulento torna-se maior pela resistência a diversos antimicrobianos disponíveis, resultado de diversas mutações por serem microrganismos presentes no ambiente, mas que podem causar infecções em hospitais (SOARES MA, et al., 2019; SERAFIM VJ, 2018).

A UTI tem se destacado por ser um ambiente com pacientes apresentando diversas formas clínicas, idades, acometimentos, grande fluxo de pessoas e doenças de base. Assim, vale ressaltar que estão envolvidos nos processos de resistência de problemas de saúde pública como o uso indiscriminado de antimicrobianos (SANTOS ABR, et al., 2019; BROOKE JS, 2012). O estudo desses microrganismos possibilita conhecer a importância deles no meio hospitalar como também as infecções causadas por eles. 
Dessa forma, este estudo buscou abordar e revisar as causas de infecções hospitalares associadas a Bacilos Gram-Negativos Não Fermentadores (BGN-NF) em Unidade de Terapia Intensiva (UTI) e seus métodos de controle e prevenção.

\section{REVISÃO BIBLIOGRÁFICA}

\section{Infecção hospitalar: um agravo a saúde do paciente}

As infecções hospitalares são problemas que estão relacionados à assistência de saúde e são consideradas as principais causas de morbidade e mortalidade hospitalar, podendo gerar prejuízos aos usuários, à comunidade e ao Estado. Representam um dos grandes problemas encontrados no controle das infecções hospitalares: os veículos de propagação dos microrganismos, podendo ser insetos, os próprios profissionais de saúde, visitantes, sistemas de condicionamento de ar, equipamentos, as bancadas, a própria alimentação, entre outros (PEREIRA CAS, et al., 2012).

O perfil de infecções ocorrentes no meio nosocomial torna-se diferente das adquiridas na comunidade, isso pelo fato da frequência, os sítios de infecção e os tipos de microrganismos isolados. Dentre as unidades hospitalares, a UTI torna-se o principal ambiente favorável à presença de agentes patogênicos, tendo cerca de $30 \%$ das infecções nosocomiais ocorrendo nesse ambiente de cuidados intensivos (MOTA FS, et al., 2018; OLIVEIRA MEF, et al., 2017).

A permanência de pacientes internados tem sido um perigoso caminho traçado até mesmo pelo uso indiscriminado em larga escala de antibióticos, selecionando cepas com mecanismos de resistência e que não permitem possibilidades e alternativas de tratamento das infecções, com isso, além do tempo prolongado do internamento, há gastos em uso de medicamentos mais caros e até mesmo o aumento da taxa do risco de mortalidade (DUARTE GEG, et al., 2017; SANTOS ABR, et al., 2019).

O custo atribuído às infecções com resistência bacteriana é considerado complexo, multidimensional com difícil estimação, pelo fato de poder variar devido ao agente etiológico, perfil de resistência, tempo do tratamento, dose utilizada, e demais fatores. Dessa forma, os custos de antimicrobianos representam entre $30 \%$ e $50 \%$ do total gasto com medicamentos em hospitais, principalmente em UTIs (LEONCIO JM, et al., 2019). O ambiente hospitalar tem se destacado como o principal reservatório dos BGN-NF (RODRIGUES TS, et al., 2018).

$\mathrm{Na}$ UTI a contaminação tem forte influência da estrutura física, elevada quantidade de equipamentos, as condições dos pacientes nos cuidados intensivos que tendem a possuir mais fatores de risco como também maiores taxas de infecção. Se a permanência exceder 15 dias ou pacientes colonizados estiverem nesse ambiente, isso poderá se tornar um alto risco de aquisição para os demais (PEREIRA CAS, et al., 2012).

Além disso, a diversidade e disseminação dos microrganismos ocasionados pelo grande fluxo de pacientes submetidos a cirurgias, doença de base, o uso dos cateteres urinários e venosos, a ventilação mecânica, perfil imunológico, a idade e o uso de medicamentos imunossupressores, como também o tratamento empírico com antibióticos e com uso de forma inadequada pode tornar pacientes suscetíveis a infecções (MOTA FS, et al., 2018; OLIVEIRA MEF, et al., 2017; SANTOS ABR, et al., 2019).

Causam infecções especialmente em extremos de idades pelo fato de possuírem um sistema de defesa fisiologicamente menos eficaz (RODRIGUES TS, et al., 2018). Em UTIs, os agentes etiológicos mais prevalentes são: Staphylococcus coagulase negativos, Staphylococcus aureus, Klebsiella pneumoniae, Enterococcus e Pseudomonas aeruginosa, com casos de mortes que variam de 9 a $38 \%$, podendo alcançar a 60\% (RODRIGUES TS, et al., 2018; OLIVEIRA MEF, et al., 2017).

\section{Características dos bacilos gram-negativos não fermentadores (BGN-NF)}

Os BGN-NF são considerados não fermentadores pelo fato de não utilizarem glicose na via fermentativa. São um grupo complexos e amplo de bactérias aeróbicas não esporuladas, podendo estar presentes no solo, plantas e água. Contudo, podem se apresentar no ambiente hospitalar, em instrumentos como umidificadores, 
ventiladores mecânicos, colchões e pele de profissionais de saúde, podendo representar aproximadamente $15 \%$ do total de microrganismos isolados em amostras clínicas (BELTRÁN JAP, et al., 2017; GREWAL US, et al., 2017).

Diversos microrganismos podem sobreviver às condições adversas necessitando apenas de um ambiente úmido para sobreviver e ter viabilidade por muitos meses (SANTOS ABR, et al., 2019). Os BGN-NF possuem muita afinidade com a água, por serem encontrados em ambiente hospitalar são considerados patógenos com grande potencial, em função da elevada capacidade de se multiplicar, higiene precária e condutas terapêuticas inadequadas como o uso indiscriminado de antimicrobianos de amplo espectro, contribuindo para o estado da morbidade dos pacientes imunocomprometidos pondo suas vidas em risco (PEREIRA CAS, et al., 2012)

\section{Aspectos da bactéria baciliforme Pseudomonas aeruginosa ( $P$. aeruginosa)}

São bacilos gram-negativos aeróbio estrito, não-esporulado, geralmente móveis, retos ou ligeiramente curvados, dispostos em pares, não utiliza carboidrato como fonte de energia pela fermentação, mas apenas pela via da oxidase. Seu crescimento ocorre em temperatura de $37^{\circ} \mathrm{C}$, no entanto, pode apresentar crescimento em temperaturas que variam de $5^{\circ} \mathrm{C}$ a $42^{\circ} \mathrm{C}$. É encontrada na água, solo, plantas e alguns animais. Importante patógeno para infecções do trato urinário, do sistema respiratório causando pneumonias, infeções de pele como foliculites, dermatites e de tecidos moles, infecções sistêmicas, ósseas, oftalmológicas (HASSUNA NA, et al., 2020; BUENAHORA RDR, et al., 2016).

O microrganismo $P$. aeruginosa possui diversos fatores de virulência que contribuem exclusivamente para sua patogenicidade, tais como, os lipopolissacarídeos, o fator de adesão, os flagelos, as exoproteases, fosfolipase $\mathrm{C}$, exotoxinas, exoenzimas $\mathrm{S}, \mathrm{T}$ e U, bem como sialidase. Possui a capacidade de formar biofilmes, o que a torna mais resistente aos antimicrobianos, neuraminidase, leucocidina, piocianinas, pioverdinas e adesinas (MENEGUETI MG, et al., 2015).

Sua resistência pode ser explicada basicamente por expressão de sistemas de bombas de efluxo, diminuição ou total inativação de porinas OprD e indução de expressão da enzima AmpC. Existem sistemas de bomba de efluxo, dentre eles o MexAB - OprM é o de maior relevância na resistência intrínseca de antibióticos, principalmente para fluoroquinolonas e a todos os beta-lactâmicos, exceto o imipeném (RODRIGUES LS, et al.,2011; FROTA OP, et al., 2011; COSTA ALP e JUNIOR ACSS, 2017).

\section{Aspectos da bactéria aeróbia Gram-negativa Acinetobacter baumannii (A. baumannii)}

Estes microrganismos pertencem à família Moraxellaceae, sua morfologia os classifica em cocobacilos gram-negativos, não esporulados, e que realizam movimentos de contração por apresentarem fímbrias polares. Possuem um metabolismo não fermentador, crescem em temperaturas de 33 a $35^{\circ} \mathrm{C}$. Assim, a $A$. baumannii pode crescer em $42^{\circ} \mathrm{C}$, o que as outras espécies não conseguem, apresentam colônias com coloração levemente rosa pela pouca oxidação de lactose, convexas, translúcidas e opacas e com positividade na catalase e negatividade na oxidase, sem motilidade. (SANTOS ABR, et al., 2019). São considerados importantes patógenos oportunistas em infecções hospitalares da UTI (ELHAM B e FAWZIA A, 2019).

Assim, a A. baumannii se destaca como um dos importantes patógenos nosocomiais gram-negativos que é resistente a múltiplas drogas, podendo ser a espécie mais comum do gênero. Pode ser responsável por muitas infecções graves, como pneumonia, sepse, bacteremia, meningite, do trato urinário, de tecidos moles e infecções de feridas, podendo diversos fatores levarem à colonização por este patógeno, como internação prolongada, procedimentos pós-cirúrgicos, tratamento prévio com antimicrobianos de amplo espectro e internação na UTI (ELHAM B e FAWZIA A, 2019; CANGUSSU EWS, et al., 2020).

As espécies de Acinetobacter podem apresentar uma diversidade de fatores de virulência, exemplos como: captação de ferro do meio ambiente, produção de cápsula polissacarídica, resistência à secagem e dessecação e podem persistir em ambientes secos e inanimados por longos períodos até mais de três semanas. Além disso, apresentam aderência à superfície através da formação de biofilmes, e aderência às células epiteliais por meio de pili (CANGUSSU EWS, et al., 2020). 
Pode apresentar resistência intrínseca à maioria das classes dos antibióticos e resistência adquirida às fluoroquinolonas, aminoglicosídeos e às cefalosporinas. Os carbapenêmicos são as drogas de escolha para tratar infecções causadas por esse microrganismo, porém, a resistência a esse fármaco já emergiu devido à produção de carbapenemases e alteração de proteínas de membrana externa da parede celular. Apesar de isolados multirresistentes serem tratados com tigeciclinas e polimixina, já foram encontrados isolados panresistentes (GREWAL US, et al., 2017).

A multirresistência adquirida por $A$. baumannii é mediada por uma diversidade de mecanismos, o que inclui a aquisição de elementos genéticos móveis, como os plasmídeos, transposons e integrons, além da transformação natural. Além disso, os outros mecanismos de resistência envolvem as bombas de efluxo, modificação do alvo, deficiência de porinas e degradação de enzimas antimicrobianas. A resistência aos betalactâmicos consiste na produção das beta-lactamases de classe A adenosina 3',5'-monofosfato cíclico, codificadas cromossomicamente (BUENAHORA RDR, et al., 2016).

\section{Aspectos da bactéria Stenotrophomonas maltophilia (S. maltophilia)}

São microrganismos aeróbicos, não fermentadores da glicose, porém oxidam a glicose e maltose, classificados como bacilos Gram-negativos de tamanho ligeiramente menor que das outras espécies do gênero Stenotrophomonas, móveis com o auxílio dos flagelos polares e apresentam colônias pigmentadas de cor amarela no meio ágar MacConkey, são catalase-positiva, normalmente oxidase-negativa, característica distintiva com o gênero, e lisina descarboxilase, são isolados frequentemente do solo, água, animais e vegetais (ADEGOKE AA, et al., 2017).

É um patógeno incomum em causar infecções em imunocompetentes, porém se destaca em infecções nosocomiais, podendo causar mortalidade que varia de $14 \%$ a $69 \%$ em pacientes com bacteremia, principalmente de imunocomprometidos, perdendo apenas para $P$. aeruginosa e $A$. baumannii (BROOKE JS, 2012). Pode causar pneumonias, bacteremias, infecções de pele e tecidos moles, infecções no trato urinário, endocardites, infecções intra-abdominais, meningites, síndromes oftalmológicas e sinusites.

Os fatores de risco incluem o uso de terapia antimicrobiana de amplo espectro como fluoroquinolonas, cefalosporinas de espectro estendido e carbapenêmicos, leucemias ou linfomas refratários, imunossupressão, permanência prolongada em UTI, radioterapia, neutropenia pós-quimioterapia $(<500$ células $/ \mu \mathrm{L}$ ), ventilação mecânica prolongada por mais de sete dias e o uso de dispositivos intravasculares (RODRIGUES LS, et al., 2011).

\section{Mecanismos de resistência dos BGN-NF}

Os antibióticos têm revolucionado o tratamento das doenças infecciosas causadas por bactérias e tem reduzido mundialmente as taxas de morbidade e mortalidade associadas a infecções desses microrganismos. No entanto, o seu mau uso poderá acelerar a resistência natural de bactérias contra esses fármacos, isso pelo fato de que no ambiente natural os antimicrobianos são sintetizados por populações de micróbios como meio de competir pelos recursos nutricionais e o espaço dentro do micro-habitat que estão ocupando (COSTA ALP e JUNIOR ACSS, 2017).

A resistência aos antibióticos é tratada como um problema na saúde pública com maior importância clínica, já que dificulta controlar as doenças infecciosas, além disso promove o aumento da morbimortalidade, como também diminui a eficácia terapêutica. Ademais, pode causar a transmissão de infecções a outras pessoas e traz risco à segurança do paciente e altos custos para os cuidados de saúde. A sintomatologia de bactérias resistentes é idêntica às de bactérias suscetíveis, o que difere é a abordagem farmacológica que se torna restrita (RODRIGUES TS, et al., 2018).

Essa resistência bacteriana é caracterizada pela capacidade de um microrganismo impedir que um antimicrobiano específico cause danos sobre ele tornando o tratamento ineficaz (SERAFIM VJ, 2018). Essas características de resistência remetem a fenômenos genéticos, ligados a genes presentes nos microrganismos que traduzem diferentes mecanismos bioquímicos impedindo a ação dos fármacos. Na UTI 
a resistência tem se tornado um dos maiores problemas enfrentados pelos profissionais de saúde, o que tem se tornado um problema grave de saúde pública devido ao grande impacto no meio econômico e social (MOTA FS, et al., 2018).

Os BGN-NF são encontrados com frequência na árvore brônquica, principalmente em pacientes com fibrose imunossuprimida e fibrose cística, o que tornou-se um problema pelo fato da alta resistência dessas bactérias a uma ampla variedade de fármacos, incluso as penicilinas, cefalosporinas, aminoglicosídeos, tetraciclinas, fluoroquinolonas, sulfametoxazol-trimetropim, carbapenêmicos e polimixinas que é utilizada no tratamento de infecções causadas por Pseudomonas aeruginosa e Acinetobacter (OLIVEIRA MEF, et al., 2017).

Em diversos microrganismos a resistência pode ser classificada em intrínseca ou natural onde a informação é de caráter hereditária, transmitida verticalmente às células filhas por meio de genes cromossômicos e que determinarão a ausência de receptores da ação de antimicrobianos numa célula bacteriana. Esse tipo de resistência pode servir como marcador para confirmar a identificação de uma bactéria, além de ajudar na monitorização de procedimentos padronizados (ARAÚJO PL, et al., 2017).

Além da resistência intrínseca, as bactérias podem sofrer mutações resultando em erros no ácido desoxirribonucleico (DNA) cromossômico podendo alterar a informação original como no processo de replicação ou por agente mutagênico como as radiações ionizantes e não-ionizantes, assim gerarão novas células com mutações específicas e que poderão ser transmitidas às gerações posteriores (COSTA ALP e JUNIOR ACSS, 2017). Dentre essas mutações, pode existir a que possibilite à bactéria gerar uma nova proteína alterada levando à resistência ao antimicrobiano possibilitando competitividade pelo ambiente.

Ademais, o biofilme é considerado um fator importante para ocorrer infecções persistentes ligadas à resistência microbiana, pois sua constituição é de uma matriz polimérica fora da célula constituída por bactérias em comunidade, podendo estar aderido às superfícies bióticas ou abióticas com capacidade se adaptar a em diversos ambientes (ARAÚJO et al., 2017). A resistência por biofilmes é considerada um novo mecanismo presentes em diversos locais como placas dentárias, cateteres e feridas traumáticas (ELHAM B; FAWZIA A, 2019).

Além disso, as bactérias utilizam mecanismos bioquímicos para resistir a ação do fármaco. A resistência por inativação enzimática é causada a partir da produção de enzimas, podendo ser por hidrólise, transferência de um grupo químico ou por processo de oxirredução. Na hidrólise um mecanismo muito conhecido é pela produção de Betalactamases que hidrolisa o anel beta lactâmico de penicilinas e cefalosporinas. Há aproximadamente identificadas, 200 tipos de enzimas Betalactamases de diferentes grupos funcionais que podem ser originadas do cromossomo plasmídios de bactérias diferentes (MENEGUETI MG, et al., 2015).

No mecanismo de reação enzimática por transferência do grupo químico, pode gerar resistência para os macrolídeos, aminoglicosídeos, fosfomicina, estreptograminas e anfenicóis, onde enzimas podem adicionar grupos químicos a pontos vulneráveis da molécula do antibiótico. Por último, no processo de oxirredução, uma enzima TeTX, diante da flavina transfere o grupo hidroxil à molécula de tetraciclina na $11^{\underline{a}}$ posição, tornando uma estrutura menos apta para sequestrar íons de magnésio que são fundamentais para a tetraciclina atingir o alvo (FROTA OP, et al., 2020).

O mecanismo de resistência mais importantes e frequentes em BGN é o da produção de enzimas como as Betalactamases ( $\beta$-lactamases). Dentre elas, destacam-se as de espectro estendido, como as betalactamases de espectro estendido (ESBL), que foram identificados mais de 180 tipos, que podem gerar resistência às penicilinas, cefalosporinas, monobactâmicos, carbapenêmicos, como também resistência aos inibidores de betalactamases, como o ácido clavulânico, o sulbactam e o tazobactam, podendo ser encontrada na família Enterobacteriaceae, $P$. aeruginosa e A. baumannii (MOTA FS, et al., 2018; OLIVEIRA MEF, et al., 2017).

Além das betalactamases, pode-se encontrar as carbapenemases, adenosina 3',5'-monofosfato cíclico (AMPc) e metalobetalactamases, que geram resistência aos betalactâmicos, inclusive os carbapenêmicos. 
Contudo, o principal problema está relacionado às cepas de resistência Acinetobacter e $P$. aeruginosa como também à família enterobacteriaceae, capazes de produzir $\beta$-lactamases de espectro estendido (ESBL) (MOTA FS, et al., 2018; OLIVEIRA MEF, et al., 2017; SANTOS ABR, et al., 2019).

Os antibióticos com alvo na membrana celular incluem as polimixinas que agem como detergentes e que interagem com moléculas de polissacarídeos na membrana externa sequestrando o cálcio e magnésio, podendo alterar sua permeabilidade e causar extravasamento do meio intracelular (DIAS VC, et al., 2020; DUARTE GEG, et al., 2018). Assim, na interferência do metabolismo celular são incluídas as sulfonamidas e o trimetropim que bloqueiam etapas de sintetização do ácido fólico, um cofator para a produção de ácido desoxirribonucleico (DNA) e ácido ribonucleico (RNA) (COSTA ALP e JUNIOR ACSS, 2017; OLIVEIRA MEF, et al., 2017).

\section{Medidas de controle e prevenção de infecções hospitalares associadas à bacilos gram-negativos não fermentadores}

As UTIs buscam atender pacientes em estado agudo ou crítico, que requerem assistência médica e de enfermagem especializadas e ininterruptas. Sendo assim, higienizar as mãos, que abrange a lavagem simples ou a antissepsia, é considerada a principal medida para controlar a disseminação de microrganismos no ambiente de assistência à saúde. Apesar dessa importância e da facilidade e simplicidade para realizar a prática da higienização das mãos, as taxas de adesão são consideradas baixas e que podem variar de acordo com as funções de trabalho e infraestrutura (SOARES MA, et al., 2019; LEONCIO JM, et al., 2019).

Muitos profissionais de saúde têm contribuído para a infecção dos pacientes pela falta de higienização adequada das mãos e a manipulação inapropriada dos procedimentos. Isso pelo fato de terem o contato direto com os pacientes podem acabar transportando organismos patogênicos de um paciente a outro, como também se auto contaminarem. Além disso, os visitantes contribuem indiretamente por adentrarem ao ambiente hospitalar transportando microrganismos do ambiente externo, como também podendo levar os mesmos do hospital para suas casas, trabalhos entre outros (COSTA ALP e JUNIOR ACSS, 2017; PEREIRA CAS, et al., 2012).

Sendo assim, é de suma importância organizar o espaço físico entre leitos e equipamentos, aplicar protocolos de limpeza dessas superfícies conforme as características do setor, acrescentar orientação ao paciente, familiares e visitantes sobre a importância da higienização de mãos e educação permanente e constante dos profissionais poderão reduzir a disseminação ambiental e contaminação de patógenos (ADEGOKE AA, et al., 2017; PEREIRA CAS, et al., 2012).

Além disso, a implementação de educação continuada sobre a relevância da higienização de mãos, a monitorização da adesão à prática de higiene das mãos, a manutenção e instalação de equipamentos, racionalidade no uso de antibióticos e recomendações com base no cuidado com os procedimentos invasivos e a promoção da higienização das mãos (SOARES MA, et al., 2019; BROOKE JS, 2012).

\section{CONSIDERAÇÕES FINAIS}

Desse modo, evidencia-se a importância da realização de triagem constante de BGN-NF nos ambientes hospitalares visando controlar e prevenir a infeção. Além disso, a busca de novos metabólitos ativos, implemento de medidas de higienização, avaliação de perfis com suscetibilidade a antibióticos, e o uso criterioso de antimicrobianos são indicados para gerenciar de forma eficaz as infecções causadas por estes microrganismos, além do controle e prevenção da disseminação de patógenos resistentes, podendo assim limitar o surgimento de resistência às múltiplas drogas.

\section{AGRADECIMENTOS}

Ao Centro Universitário Mauricio de Nassau, Fortaleza - CE. 


\section{REFERÊNCIAS}

1. ADEGOKE AA, et al. Stenotrophomonas maltophilia as an Emerging Ubiquitous Pathogen: looking beyond contemporary antibiotic therapy. Frontiers in Microbiology, 2017; 8: 1-18.

2. ALVIM ALS, et al. Avaliação das práticas de higienização das mãos em três unidades de terapia intensiva. Revista de Epidemiologia e Controle de Infecção, 2019; 9(1): 1- 5.

3. ARAÚJO PL, et al. Prevalencia de la infección relacionada con la asistencia a la salud em pacientes hospitalizados en unidad de cuidados intensivos. Enfermería Global, 2017, 291-303.

4. BELTRÁN JAP, et al. Perfil de resistência antimicrobiana en bacilos Gram negativos no fermentadores aislados en fuentes hídricas. Revista Médica Risaralda, 2017; 23(2): 38-42.

5. BROOKE JS. Stenotrophomonas maltophilia: an emerging global opportunistic pathogen. Clinical Microbiology Reviews, 2012; 25(1): 2-41

6. BUENAHORA RDR, et al. Acinetobacter baumannii: patógeno multirresistente emergente. Medicas UIS, 2016; 29(2):113-135.

7. CANGUSSU EWS. Importância do Acinetobacter baumannii no ambiente hospitalar. Journal of Biotechnology and Biodiversity, 2020; 8(1): 41-46.

8. COSTA ALP; JUNIOR ACSS. Resistência bacteriana aos antibióticos e Saúde Pública: uma breve revisão de literatura. Estação Científica, 2017; 7(2): 45-57.

9. DIAS VC, et al. Prevalência e resistência a antibióticos de Stenotrophomonas maltophilia em amostras clínicas: estudo epidemiológico de 10 anos. Hu Revista, 2020; 45(4): 402-407.

10. DUARTE GEG, et al. Resistance profile of microorganisms isolated in the Microbiology Service of the Hospital Nacional in the year 2017. Del Nacional, 2018; 10(2): 21-38.

11. ELHAM B; FAWZIA A. Colistin resistance in Acinetobacter baumannii isolated from critically ill patients: clinical characteristics, antimicrobial susceptibility and outcome. African Health Sciences, 2019; 19(3): 2400-2406.

12. FROTA OP, et al. Effectiveness of clinical surface cleaning and disinfection: evaluation methods. Revista Brasileira de Enfermagem, 2020; 73(1): 1-6.

13. GREWAL US, et al. Antibiotic susceptibility profiles of non-fermenting gram-negative Bacilli at a Tertiary Care Hospital in Patiala, India. Nigerian Postgraduate Medical Journal, 2017; 24(2): 121-125.

14. HASSUNA NA, et al. Virulence Constitution of Multi-Drug-Resistant Pseudomonas aeruginosa in Upper Egypt. Infection and Drug Resistance, Minia, 2020; 587-595.

15. LEONCIO JM, et al. Impacto das infecções relacionadas à assistência à saúde nos custos da hospitalização de crianças. Revista da Escola de Enfermagem da USP, 2019; 53: e03486.

16. MENEGUETI MG, et al. Evaluation of Nosocomial Infection Control Programs in health services. Revista Latinoamericana de Enfermagem, 2015; 23(1): 98-105.

17. MOTA FS, et al. Profile and prevalence of antimicrobial resistance of negative-Gram bacteria isolated from intensive care patients. Revista Brasileira de Análises Clínicas, 2018; 50(3), 1-12.

18. OLIVEIRA MEF, et al. Resistance of non-fermenting Gram-negative bacilli isolated from blood cultures from an emergency hospital. Jornal Brasileiro de Patologia e Medicina Laboratorial, 2017; 87-91.

19. PEREIRA CAS, et al. Pesquisa de bacilos Gram negativos não fermentadores presente em torneiras de um hospital privado do município de volta redonda, RJ. Revista Episteme Transversalis, 2012; 3(1): 1-10.

20. POZZATO RS; PARISI MM. Clinical and microbiological profile of hospital infection cases occurred in a medium-sized hospital of the northwest of Rio Grande do Sul. Revista Brasileira de Análises Clínicas, 2018; 50 (3): 1-9.

21. RODRIGUES LS, et al. Stenotrophomonas maltophilia: resistência emergente ao smx-tmp em isolados brasileiros. uma realidade? Jornal Brasileiro de Patologia e Medicina Laboratorial, 2011; 47(5): 511-517.

22. RODRIGUES TS, et al. Resistência bacteriana à antibióticos na unidade de terapia intensiva: revisão integrativa. Revista Prevenção de Infecção e Saúde, 2018; 4: 1-17.

23. SANTOS ABR, et al. Prevalência, perfil microbiológico e sensibilidade aos antimicrobianos de bacilos Gram-negativos não fermentadores em pacientes internados em hospital terciário de João Pessoa-2015. Journal of Infection Control, 2019; 8(3): 96-101.

24. SERAFIM VJ. Genes bacterianos de resistência no meio ambiente. Revista Unilago, 2018; 1(1): 1-10.

25. SOARES MA, et al. Microrganismos multirresistentes nas mãos de profissionais de saúde em Unidades de Terapia Intensiva. Revista de Epidemiologia e Controle de Infecção, 2019; 9(3): 187-192. 